\title{
COMBUSTION OF HYDRAZINIUM NITROFORMATE BASED COMPOSITIONS
}

\author{
J. Louwers", G.M.H.J.L. Gadiot ${ }^{\ddagger}$ \\ Research Group Rocket Technology, TNO Prins Maurits Laboratory \\ P.O. Box 45, 2280 AA Rijswijk, the Netherlands \\ M. Versluis ${ }^{\S}$, A.J. Landman", Th. H. van der Meer ${ }^{\sharp}$, D. Roekaerts ${ }^{* *}$ \\ Thermal and Fluids Sciences, Department of Applied Physics, Delft University of Technology \\ P.O. Box 5046, 2600 GA Delft, the Netherlands
}

\begin{abstract}
The combustion of hydrazinium nitroformate (HNF) and HNF with additives has been studied in window bombs. HNF burns with a high regression rate $(40 \mathrm{~mm} / \mathrm{s}$ at $10 \mathrm{MPa})$ and a high burn rate exponent. A slope break is observed around $2 \mathrm{MPa}$ (from $\mathrm{n}=0.95$ to $\mathrm{n}=0.85$ ). The surface temperature increases with increasing pressure: at $0.1 \mathrm{MPa} \mathrm{T}_{\mathrm{s}}=530 \mathrm{~K}$, and at $1 \mathrm{MPa} \mathrm{T}_{\mathrm{s}}=680 \mathrm{~K}$. Thermocouple measurements show a bend in the condensed phase temperature profile. This bend is attributed to cracks that form during combustion. Samples containing $20 \%$ aluminum have about $30 \%$ higher burn rate at $1 \mathrm{MPa}$ than neat HNF. At low pressures, a small amount of residue was found after combustion of these samples. However, at 2 MPa the pellets combust without residue. Samples containing 5\% graphite have a constant pressure exponent, $\mathrm{n}=0.81$. Around $10 \mathrm{MPa}$ the burn rate becomes equal to that of neat HNF. Also paraffin-based combinations burn with a low pressure exponent $n=0.81$ at low pressures. At higher pressures an increase in the pressure exponent was found, $\mathrm{n}=1.09$.
\end{abstract}

\section{INTRODUCTION}

More energetic propellants may increase the payload mass of space launchers, and increase the range of missiles. Therefore there is a continuous effort to increase the performance of solid propellants. High performance propellants have high flame temperatures and combustion products with low molecular weight. Partially replacing the AP in composite propellants by RDX and HMX increases the performance. However the performance can be further increased by replacing AP with "new" more energetic oxidizers like ammonium dinitramide (ADN), hydrazinium nitroformate $\left(\mathrm{N}_{2} \mathrm{H}_{4} \cdot \mathrm{C}\left(\mathrm{NO}_{2}\right)_{3}\right.$, $\mathrm{HNF}$ ) and hexanitrohexaazaisowurtzitane (HNIW, or CL-20, not a real oxidizer, but an energetic filler like RDX and HMX) [1]. These new oxidizers are also chlorine-free, which reduces the impact on the environment compared to AP-based compositions. Replacing the inert binders by energetic binders like GAP, BAMO, PolyNimmo and PolyGlyn can further increase the performance of these propellants.

HNF was part of a large research project for new high-performance propellants in the United States in the 60 's and 70 's. HNF appeared to be incompatible with the double bonds in unsaturated binders like HTPB [2]. The recent commercial production of saturated energetic binders like GAP, led to a renewed interest in HNF. Propellants based on hydrazinium nitroformate (HNF), an energetic binder like GAP or BAMO and aluminum have a substantially higher potential performance than any other solid propellant [3]. Compared to AP-based propellants the performance gain is about $5 \ldots 7 \%$. In comparison with ADN-compositions, HNF-based

\footnotetext{
*Ph.D. student, corresponding author, email: louwers@pml.tno.nl, phone: +31-15-2843367, fax: +31-152843958

$¥$ Propulsion engineer

$\S_{\text {Research fellow }}$

I Student

* Associate professor

** Professor

Copyright (C) 1998 by TNO-Prins Maurits Laboratory and Delft University of Technology. Published by the American Institute of Aeronautics and Astronautics, Inc. with permission.
} 
propellants have about 1 to $1.5 \%$ performance gain. These differences in performance, in terms of payload mass, are very large. It was demonstrated recently in a series of comparative experiments that a typical HNF/Al/GAP propellant indeed has a higher performance than a state-of-the-art AP/A1/HTPB propellant formulation [4].

Since HNF's revival many issues have been studied like compatibility, safety aspects, toxicity, morphology, and propellant development. Each of these aspects have been described elsewhere, see e.g. Ref's [4-7]. Initial experiments were promising and the lab scale synthesis of HNF was scaled up to pilot scale. Aerospace Propulsion Products (APP) now has a maximum production capacity of 100 to 300 $\mathrm{kg} /$ year.

Apart from the practical propellant research, also more fundamental combustion studies have been carried out. Von Elbe et al. studied the combustion of loosely packed HNF with a TMD of $75 \%$ in different tube sizes [8]. They concluded that a particle of HNF larger than 100 micron in a composite propellant deflagrates independently of the embedding matrix at $6.8 \mathrm{MPa}$. Nucleate centers of pyrolysis were found at the melting point of $\mathrm{HNF}$. $\mathrm{NO}_{2}$ was detected as one of the major decomposition products of HNF. The $\mathrm{NO}_{2}$ was reported to react with the HNF, generating more $\mathrm{NO}_{2}$ molecules then used in this reaction. Thermocouple measurements of the condensed phase combustion wave showed three distinct zones [9]. First inert heating up to $120^{\circ} \mathrm{C}$, formation of gas bubbles between $120^{\circ} \mathrm{C}$ and $260^{\circ} \mathrm{C}$, and then gasification above $260^{\circ} \mathrm{C}$.

Williams and Brill studied the decomposition of HNF using their T-jump apparatus [10]. Below $260^{\circ} \mathrm{C} \mathrm{HNF}$ was found to decompose endothermically into hydrazine and nitroform. At higher temperatures only small molecules were detected $\left(\mathrm{NO}, \mathrm{CO}_{2}, \mathrm{H}_{2} \mathrm{O}, \mathrm{N}_{2}\right.$ and $\mathrm{H}_{2}$ ).

Parr and Hanson-Parr studied neat HNF and HNF sandwich flames by laser-induced fluorescence (LIF) and emission [11,12]. The neat HNF flame was reported to be very short, with most chemical reactions occurring in a region up to $0.5 \mathrm{~mm}$ from the burning surface. The sandwich experiments showed that even non-energetic binders were consumed at $1 \mathrm{~atm}$. At higher pressures, the non-energetic binders are left behind. For these binders the decomposition products escape through the diffusion flame. Energetic binders were found to keep up with the HNF surface, producing a stronger diffusion interaction.

Finlinson measured the laser recoil of HNF at pressures up to $6 \mathrm{~atm}$ [13]. The thrust oscillations were found to be comparable with HMX. The thrust oscillations decreased $50 \%$ in amplitude as the pressure increased from $1 \mathrm{~atm}$ to $4 \mathrm{~atm}$. The laser- assisted regression rates were also determined. The slope of the burn rate vs. laser flux was found to be nearly the same at each pressure.

The neat HNF burn rate and temperature sensitivity have been reported by Finlinson and Atwood [14]. HNF was found to burn with a very high regression rate $(>30 \mathrm{~mm} / \mathrm{s}$ at $7 \mathrm{MPa})$. The burn rate exponent is high, $n=0.83$. The temperature sensitivity was found to be $\sigma_{\mathrm{p}} \sim 0.12 \% / \mathrm{K}$, comparable to that of HMX and RDX, and about half the value of ADN's temperature sensitivity. The low pressure and sub-atmospheric regression was studied by Louwers et al. [15]. Self-sustained combustion was obtained at pressures as low as $0.03 \mathrm{MPa}$.

The thermophysical properties of HNF have been measured by Hanson-Parr and Parr [16]. Up to the melting temperature of HNF $\left(124^{\circ} \mathrm{C}\right)$ the thermal diffusivity is a continuous function of temperature, with slight positive temperature dependence. At $20^{\circ} \mathrm{C}$ a value of $\alpha_{c}=1.64 \cdot 10^{-3} \mathrm{~cm}^{2} / \mathrm{s}$ was measured.

HNF research is not limited to the USA and Europe only. In the former Soviet Union, Koroban et al. studied the kinetics and mechanisms of the thermal decomposition of HNF in the temperature range 70 $100^{\circ} \mathrm{C}$ [17]. In Japan, HNF was synthesized by Hatano et al [18]. HNF was found to be more sensitive to friction than RDX and HMX. However, the drop tests and electrostatic spark tests showed no definite tendency. Anan and Harada studied HNF/HTPB propellants [19].

Several combustion models for HNF have been presented. The steady combustion of HNF was modeled by high activation energy in the condensed phase, and low activation energy in the gas phase [20]. This proved to give very good agreement with experimental data on regression rate, temperature sensitivity, and laser-assisted combustion. Also the unsteady combustion of HNF has been modeled by Quasi-Steady gas phase Homogeneous One Dimensional (QSHOD) models [21,22]. These models showed good agreement with the laser-recoil experiments of Finlinson [13].

This work focuses on the combustion of neat $\mathrm{HNF}$, and that of HNF-based composition. Several simple additives have been mixed with HNF and pressed to small pellets. The effect of these additives on the combustion is studied. The intention of this study is to obtain a better knowledge of the combustion of HNF propellants. First the experimental set-up will be discussed. Then the manufacturing of the samples is addressed. This includes some hazard assessment tests of the obtained material. Experimental results on measured regression rate, condensed phase temperature profiles, and flame observations will then be discussed. 


\section{EXPERIMENTAL}

Two different set-ups have been used in this study. At high pressures $(>5 \mathrm{MPa})$ the regression rates are measured in a window strand burner at TNO/PML. This strand burner is equipped with three polycarbonate (PC) windows of $150 \times 15 \mathrm{~mm}^{2}$ and a thickness of $12 \mathrm{~mm}$. Maximum pressure in this strand burner is $20 \mathrm{MPa}$. In this apparatus samples with a diameter of $9 \mathrm{~mm}$ and a length of $20 \mathrm{~mm}$ are burned. Ignition takes place by means of a nichrome wire. The regression rates are obtained from the recorded video images.

Low pressure experiments $(<5 \mathrm{MPa})$ are carried out at Delft University of Technology. This set-up uses a window bomb, which was designed for non-intrusive measurements (like laser-induced fluorescence, emission, and absorption measurements). Figure 1 shows a mechanical drawing of this bomb. The bomb is equipped with 4 sapphire windows of $50 \mathrm{~mm}$ diameter and $6 \mathrm{~mm}$ thickness, which are capable of withstanding pressures up to $5 \mathrm{Mpa}$ with a safety factor of 3 . These UV transparent windows are used for optical access of the laser beams, for transmission of the fluorescence signals and allow the monitoring of the combustion process. Before, during and after combustion the bomb is purged with nitrogen. Ignition and laser-assisted burning is accomplished by a $\mathrm{CO}_{2}$-laser, which enters the bomb through a $10 \mathrm{~mm}$ thick zinc selenide ( $\mathrm{ZnSe}$ ) window on top of the bomb. The $\mathrm{ZnSe}$ window is flushed with nitrogen to prevent hot combustion gases reaching the window. Baffles are installed to prevent recirculation of the combustion gases. Pellets are placed on a post, which can easily be inserted through the bottom of the bomb. Several types of posts have been designed, e.g. to allow access for microthermocouple wires, allow cooling or heating of the pellet, and accommodate an ultrasound transducer to measure the regression rate [22]. Because of the limited nitrogen supply in this bomb, smaller samples with a diameter of $6 \mathrm{~mm}$ are burned in this. Typical height of these samples is 3 to $6 \mathrm{~mm}$.

Figure 2 shows a schematic overview of the experimental setup. A Coherent Diamond G-50 $\mathrm{CO}_{2}$ laser with an average output power of $50 \mathrm{~W}$ is used to ignite the pellets. The $\mathrm{CO}_{2}$ laser is able to ignite the pellets in pulses shorter than $100 \mathrm{~ms}$ under all conditions. The laser is controlled by an AED LC-C50 controller, which allows modulation of the laser signal. A negative $\mathrm{ZnSe}$ lens diverges the laser beam to the pellet diameter. The pressure in the bomb is measured with a pressure transducer (Omega PX213; range 1-1000 Psi). The combustion process is monitored by a color CCD camera (Hunt HTC-340). Video images are recorded on a digital video recorder (Sony DHR-1000). Burn rates are determined from the video recordings. Emission is collected and
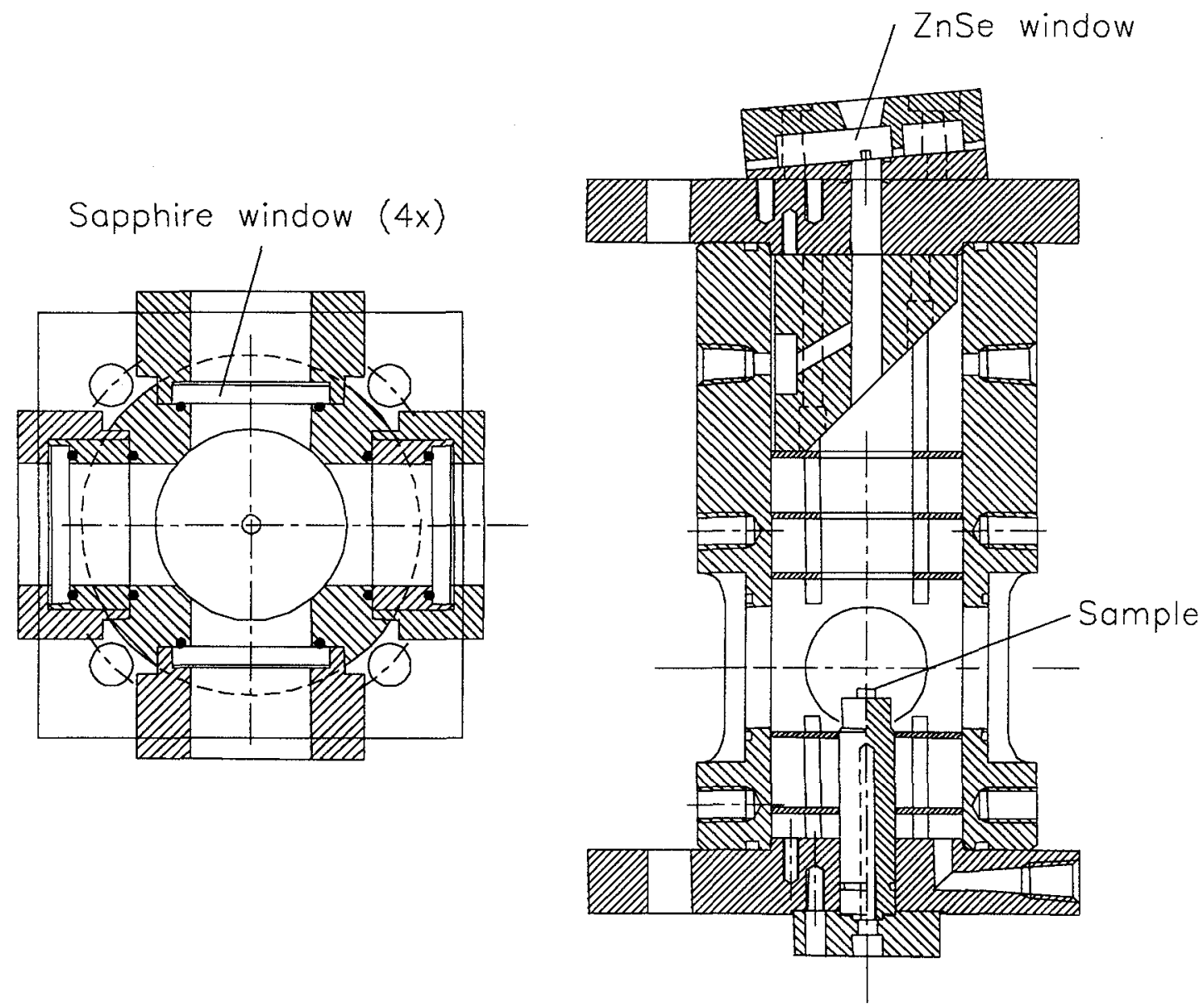

Figure 1: Mechanical drawing of the high-pressure bomb. 
focused on the entrance slit of a high-resolution spectrometer (Jobin-Yvon THR-1000; $2400 \mathrm{gr} / \mathrm{mm}$ grating) equipped with an intensified diode array detector (Spectroscopy Instruments IRY 1024). The fluorescence can also be monitored on a lowresolution spectrometer (Jarrel Ash Monospec 18; $1200 \mathrm{gr} / \mathrm{mm}$ ) also equipped with an intensified photodiode array detector (Princeton Instruments IPDA 1024). Both diode arrays use separate pulsers (Princeton Instruments FG-100) and share a common controller (Princeton Instruments ST-120). A Stanford Research System pulse/delay generator (DG535) functions as a master clock and controls experiment, lasers and data acquisition timing. Analog measurements are carried out using a 12-bit, 8 channel data acquisition board (National Instruments PCI-1200). The typical sampling rate is $1 \mathrm{kHz}$. All data acquisition and processing software is written in LabVIEW ${ }^{\circledR}$.

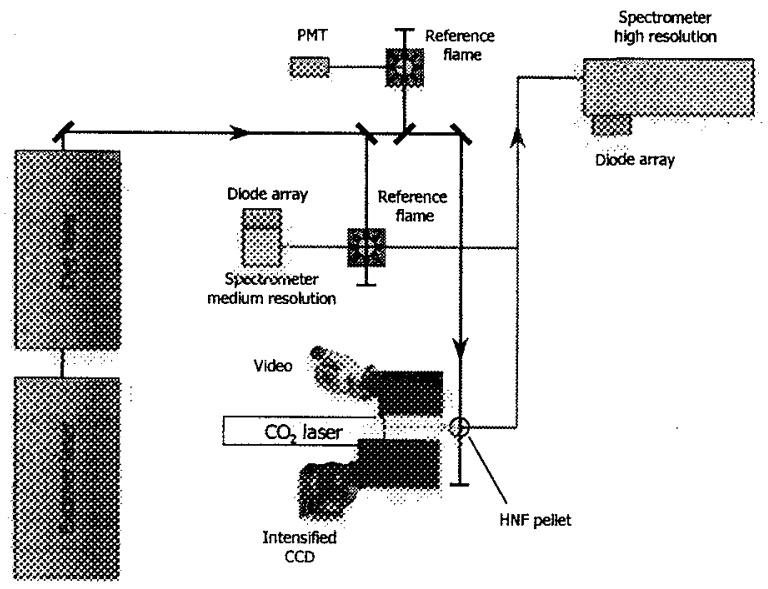

Figure 2: Schematic overview of the experimental setup.

For the low pressure experiments the samples were not inhibited. At higher pressures inhibition was found to be necessary to prevent side burning. A thin layer of Molycote 111 grease was applied on the sides a few minutes before the experiment. This proved to be a very efficient method to prevent ignition at the sides.

\section{HNF PELLETS}

\section{MANUFACTURING}

Experiments with HNF at NAWC have shown that pressing of neat HNF pellets can be done safely. The pressure employed at NAWC is $40-60$ kPsi (276-414 MPa). TMD of these pressed samples is $93-96 \%[9,11]$.

For the experiments described here, the press shown in Fig. 3 is used. Because HNF presses relatively easy (soft material), no solvent was used. To verify how the TMD varies with pressing pressure, pellets were pressed at different pressure, see Fig. 4. Figure 5 shows some of the pellets obtained by the pressing. Typical pressure used for manufacturing of the pellets is $200 \mathrm{MPa}$.

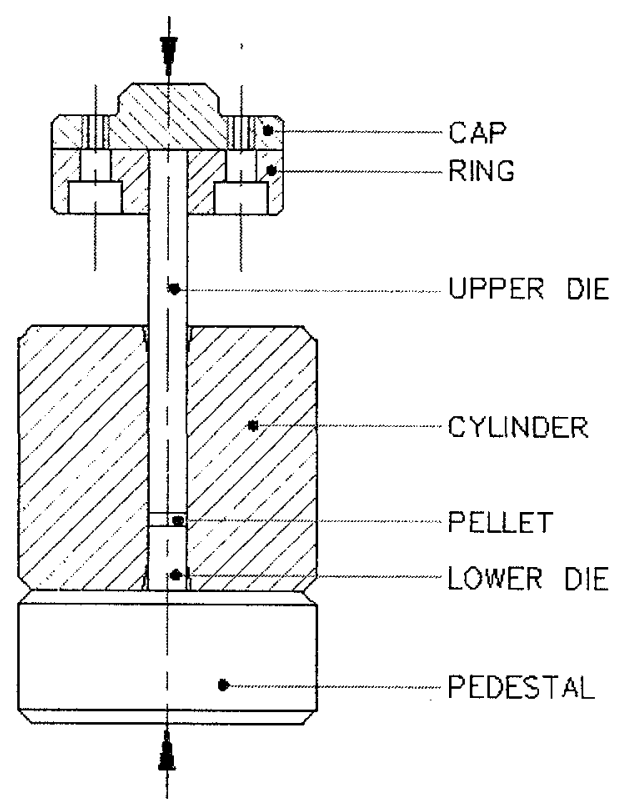

Figure 3: Press for pressing pellets.

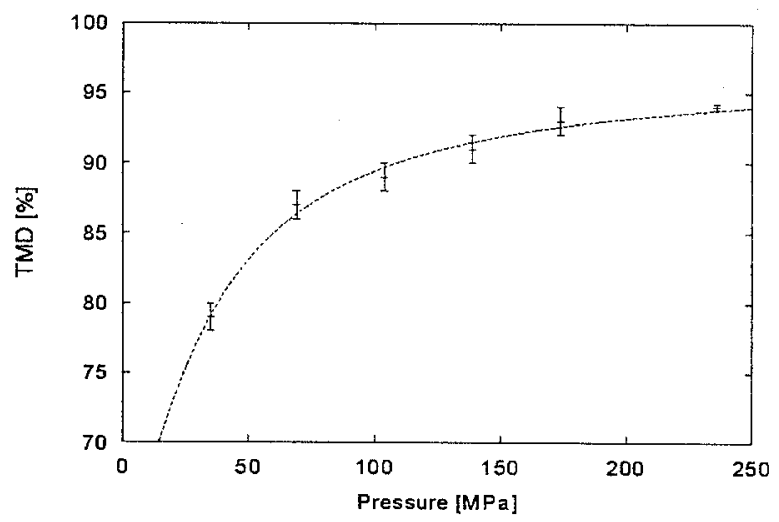

Figure 4: Neat HNF TMD as function of applied pressing pressure.

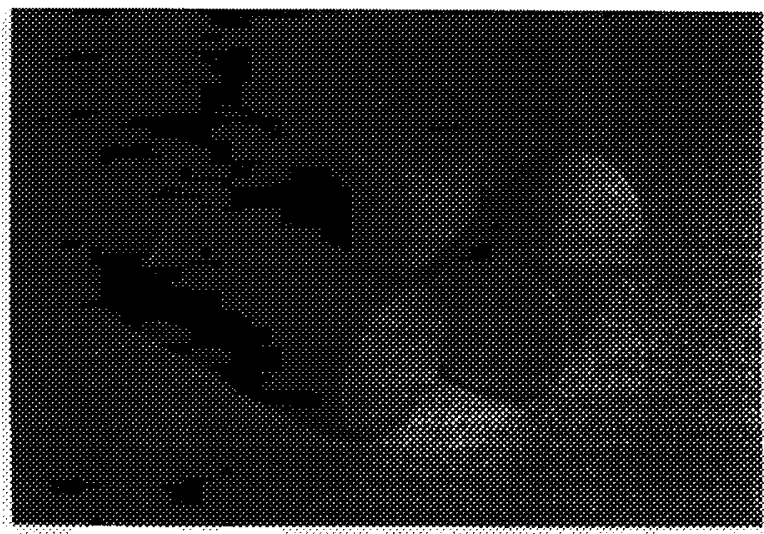

Figure 5: Pressed HNF Pellets 
Visually, the pressed material has a very smooth structure. When viewed under an electron microscope the image is different, see Fig. 6. The individual crystals (app. $100 \mu \mathrm{m}$ ) are not observed anymore, and the pellet looks like a single crystal (with voids). HNF has a tendency to evaporate under vacuum. Therefore it is important to obtain the desired images in the electron microscope quickly, before extensive evaporation has taken place.

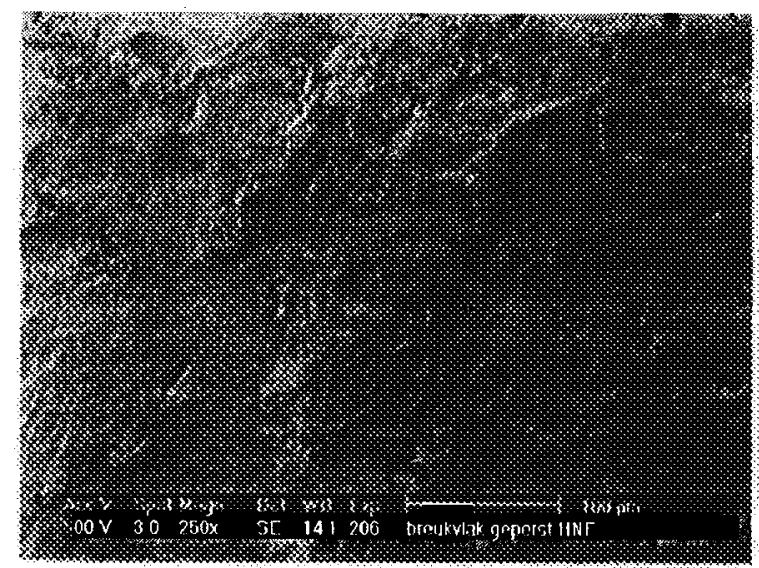

Figure 6: Fracture of a HNF pellet (electron microscope).

The results from Fig. 4 suggest that very high pressing pressures are needed to attain a TMD close to $100 \%$. However, the maximum pressure is limited by the structural strength of the press. The tempered steels used for the press dies allow up to about $400 \mathrm{MPa}$. In an attempt to obtain densities closer to the theoretical maximum density $\left(1860 \mathrm{~kg} / \mathrm{m}^{3}\right)$, several samples have been pressed in vacuum. However this did not result in higher density of the pellets. The small voids present in between the needle-shaped crystals are thought to be the origin of the voids in the pressed pellets. During pressing only the touching crystal surfaces melt and form a very strong structure. This structure is locally stronger then the applied pressure, and prevent the voids from collapsing.

\section{HAZARD ASSESSMENT TESTS}

HNF's purity and morphology are considered to be important factors of its hazard characteristics. Two convenient methods of measuring the sensitivity are the friction and impact tests. To verify whether the hazard characteristics of HNF pellets are essentially different from HNF powder, friction and impact of the pellets have been determined.

The friction and impact tests are carried out according to a standardized method (UN ST/SG/AC.10/11). According to this method, the sample material is pulverized before testing. However, crushing the pellets may not yield the desired sensitivity parameters of the pellets. Therefore two types of material have been evaluated:
- Sanded HNF pellets; some HŃ pellets were sanded on \#100 sanding paper. This yields very small crystals $(\approx 8-10 \mu \mathrm{m}$, which are not needleshaped any more), see Fig. 7. Because of the sanding action very rough surfaces are produced. During sanding no ignition or tend to ignite was observed.

- Neat HNF pellets; as pressed. Because of the shape of the samples, these tests are not according to the standardized method. For the impact testing, $6 \mathrm{~mm}$ diameter, $3 \mathrm{~mm}$ tall pellets were used. For the friction tests small HNF disks were pressed of $12.3 \mathrm{~mm}$ diameter, and $1 \mathrm{~mm}$ thickness.

The results of the hazard assessment tests are summarized in Table 1. It is concluded that the friction sensitivity is hardly changed by the pressing. However the impact sensitivity changes significantly. The pellets show a decreased sensitivity to impact, whereas the sanded pellets are very sensitive to impact. This can be attributed to the amount of energy per unit mass that is absorbed on impact. It is remarkable how small the effect of the physical geometry is on the friction sensitivity. This indicates that the friction sensitivity is species determined, rather than geometry determined. It is therefore expected that changing the crystal shape can not further decrease the friction sensitivity of $\mathrm{HNF}$. Of course the purity of HNF may still be an important parameter.

Table 1: Results of hazard assessment tests.

\begin{tabular}{|l|cc|}
\hline $\begin{array}{l}\text { Material } \\
\text { Friction } \\
{[N]}\end{array}$ & $\begin{array}{c}\text { Impact } \\
{[N m]}\end{array}$ \\
\hline HNF powder & $\mathbf{1 6 - 2 4}$ & $\mathbf{2 0}$ \\
\hline HNF sanded pellet & $\mathbf{1 6}$ \\
\hline HNF pellets & $\ldots$
\end{tabular}

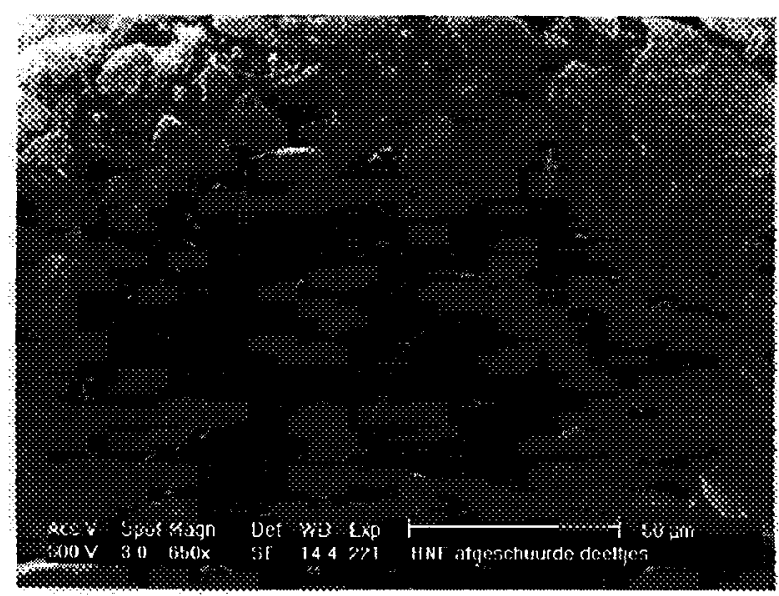

Figure 7: Sanded HNF (electron microscope). 


\section{COMBUSTION OF NEAT HNF}

\section{BURN RATE}

As already mentioned, neat HNF burns with a very high burn rate, and high burn rate exponent. Figure 8 shows the measured regression rate of neat pressed HNF pellets. The two different window bombs already described have been used to measure the regression rates. The figure shows a slope break around $2 \mathrm{MPa}$ from $\mathrm{n}=0.95$ to $\mathrm{n}=0.85$ at higher pressures. Also shown in the figure is the data obtained at NAWC [14]. Agreement with this data is good. The regression rate of HNF is very dependent on its purity [23]. This is an indication that the APPHNF has the same purity as the US-HNF, which was produced in the $60^{\prime}$ s.

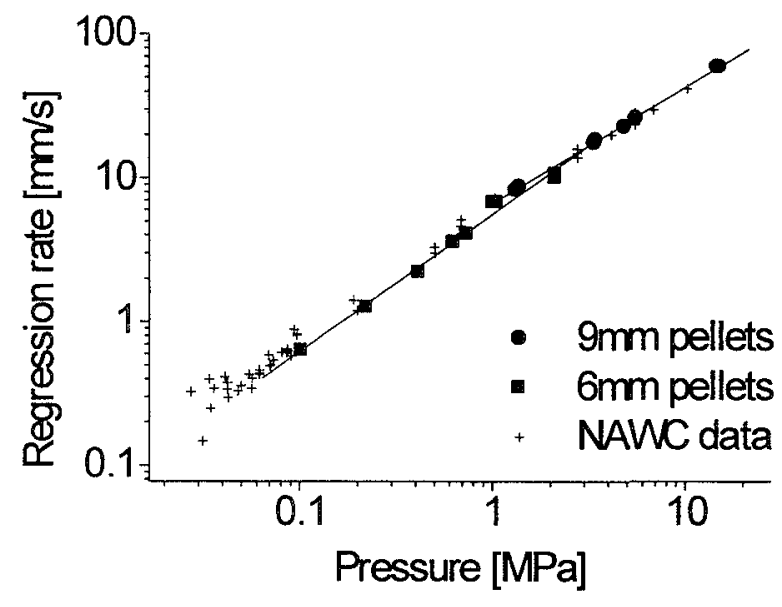

Figure 8: Regression rate of neat HNF.

\section{MICRO-THERMOCOUPLE MEASUREMENTS}

The condensed phase temperature profiles have been measured by micro-thermocouples $(5 \mu \mathrm{m}$ foil, type $\mathrm{K}, \mathrm{RdF}$ corp.). The thermocouples are assembled between two pellets halves. To ensure that the thermocouple junction emerges at the surface first, pellets were pressed with two opposing angles, see Fig. 9. To reduce heat loss the angle is large, $160^{\circ}$. The two halves are hold together by a small amount of paraffin wax around the outside of the sample.

A typical thermocouple trace at latm. is shown in Fig. 10. After ignition by the $\mathrm{CO}_{2}$-laser the condensed phase is heated by conduction from the burning surface. At $340-350 \mathrm{~K}$ a bend in the curve appears. At that moment the thermocouple is not yet visible at the burning surface. Around $400 \mathrm{~K}$ the thermocouple becomes visible. However, the thermocouple is not yet at the burning surface but is observed through the transparent burning surface. The melting temperature of HNF is $396 \mathrm{~K}$, which agrees very well with the first observation around $400 \mathrm{~K}$. Because of the surface tension, the ribbon foil sticks to the burning surface, resulting in a reasonably

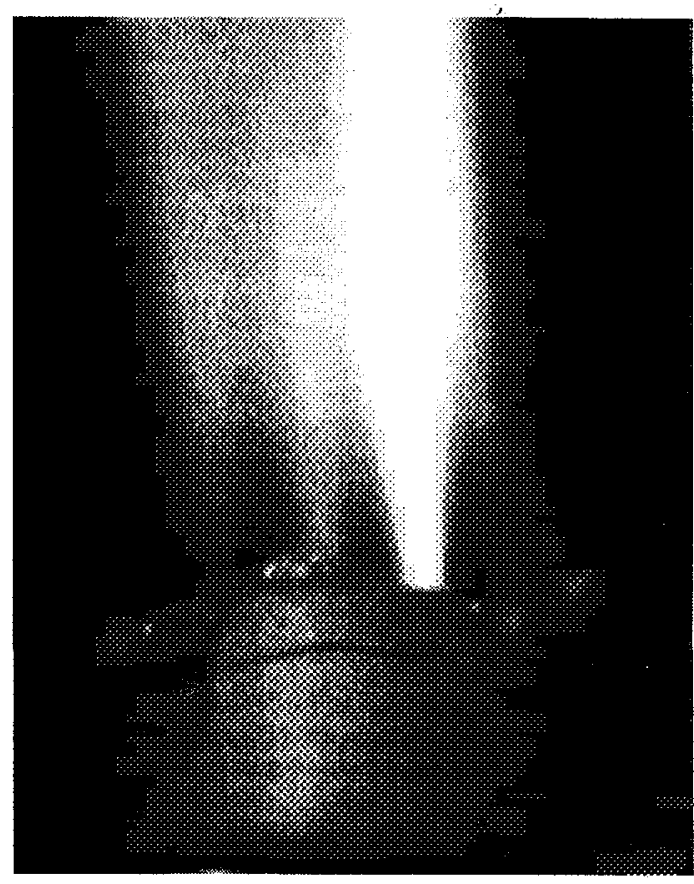

Figure 9: 5um thermocouple positioned between two pressed pellets. The bright flame is caused by $\mathrm{Na}^{*}$ emission from a small amount of $\mathrm{NaCl}$ impurities. Note the paraffin wax holding the two sample halves together.

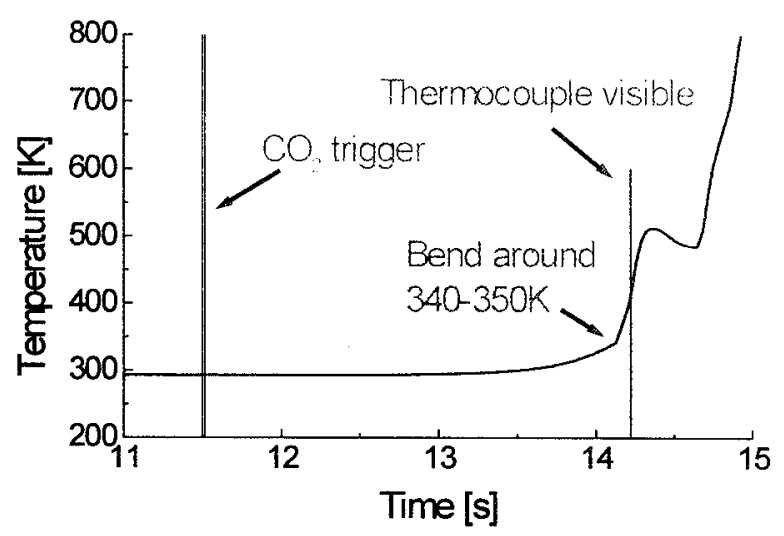

Figure 10: Thermocouple trace of microthermocouple embedded in HNF pellet (1 atm).

constant temperature. The tension at the thermocouple wires becomes stronger because of the regressing surface. If the tension is high enough, the thermocouple enters the gas phase with a very high temperature gradient.

The measured surface temperature as function of pressure is shown in Fig. 11. The surface temperature is seen to increase with increasing pressure. Because of the very steep temperature gradients in the condensed and gas phase of HNF, we did not yet succeed in determining the surface temperature at pressures above $1.0 \mathrm{MPa}$. McHale and Von Elbe measured a surface temperature of $553 \mathrm{~K}$ at ambient pressure of loosely packed HNF [7b]. The pressed samples show a surface temperature of $530 \mathrm{~K}$ at $1 \mathrm{~atm}$. 


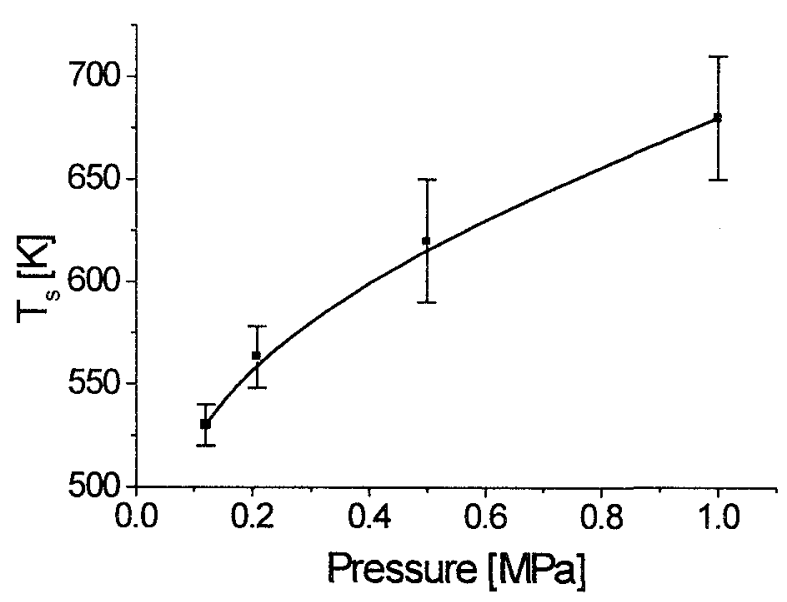

Figure 11: Surface temperature of neat HNF as function of pressure.

The strange bend around $350 \mathrm{~K}$ in Fig. 10 is caused by an interaction between the combustion wave and mechanical effects in the condensed phase [22]. Figure 12 shows the elongation of a pressed HNF-pellet as function of the temperature (uniform heating). It is seen that around $80^{\circ} \mathrm{C}$ the expansion increases strongly with temperature. Because of the non-uniform heating in the combustion wave, stresses builds up in the sample. If the stress is strong enough a crack parallel to the burning surface is formed, see Fig. 13. This causes a decrease of the thermal conductivity, which explains the upward bend in the measured temperature profile. DSC measurements of $\mathrm{HNF}$ do not show any indication of a phase transition at $80^{\circ} \mathrm{C}$. Therefore it is assumed that the sudden expansion is caused by the release of stresses present due to the pressing of the pellets. The cracks were only observed in the $9 \mathrm{~mm}$ samples, and not in the $6 \mathrm{~mm}$ samples. The larger samples have a larger volume to area ratio. This causes higher internal stresses in the larger samples.

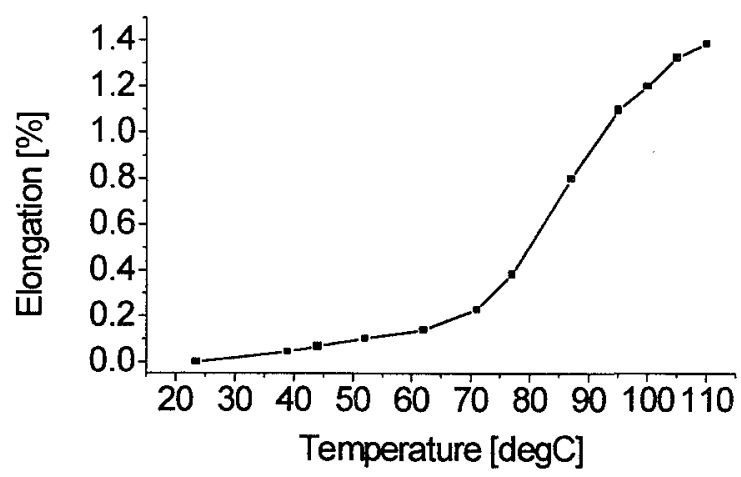

Figure 12: Elongation of a HNF pellet as

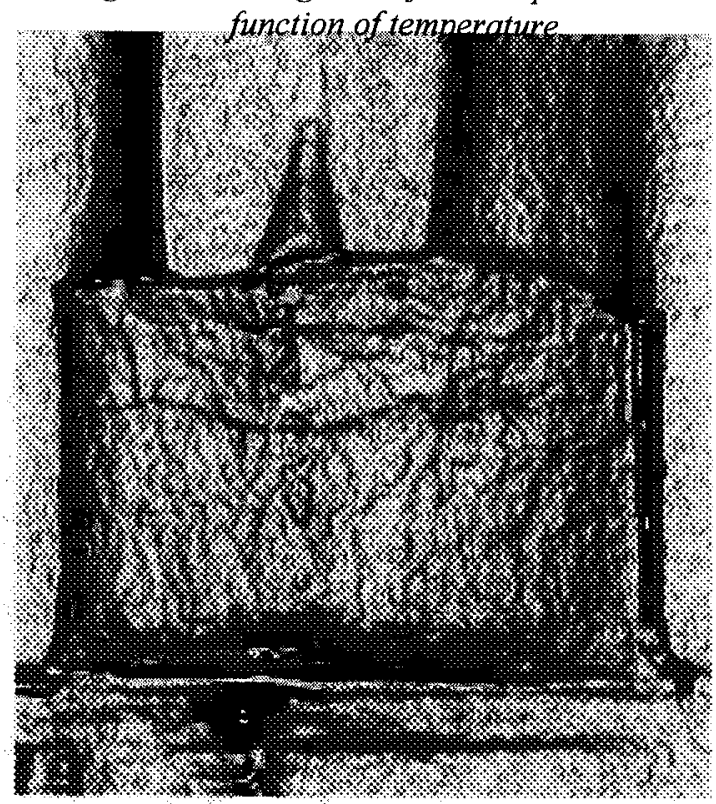

Figure 13: Formation of cracks parallel to the burning surface (image has been edge filtered to increase contrast).

\section{EMISSION}

Emission spectroscopy is a helpful tool to survey the presence of specific atomic and molecular (mostly diatomic) species and their distributions in a flame. The emitted light is dispersed in a spectrometer and electronic transitions are identified from the literature.

The neat flame HNF was already described in Ref.[11]. Apart from the narrow flame zone above the surface, the flame was found to be yellowish and bluish. The yellow emission was attributed to chemiluminescence from $\mathrm{NO}_{2}$. The bluish emission was attributed to a mixture of $\mathrm{CH}, \mathrm{CN}$ and $\mathrm{NH}$. To evaluate the presence of these radicals the emission spectrum of HNF was measured with the low resolution spectrometer.

The UV emission spectrum in Fig. 14 shows some important diatomic combustion intermediates. It shows the well-known $\mathrm{OH}(280$ and $310 \mathrm{~nm})$ and $\mathrm{CH}$ (430 $\mathrm{nm}$, blue natural gas flame) emission bands. In addition, it shows the NH (340 nm) and CN (380 nm) bands, typically found in propellant emission spectra. In the deep-UV (200-270 $\mathrm{nm}$ ) intense emission bands of $\mathrm{NO}$ and/or $\mathrm{O}_{2}$ are visible. 


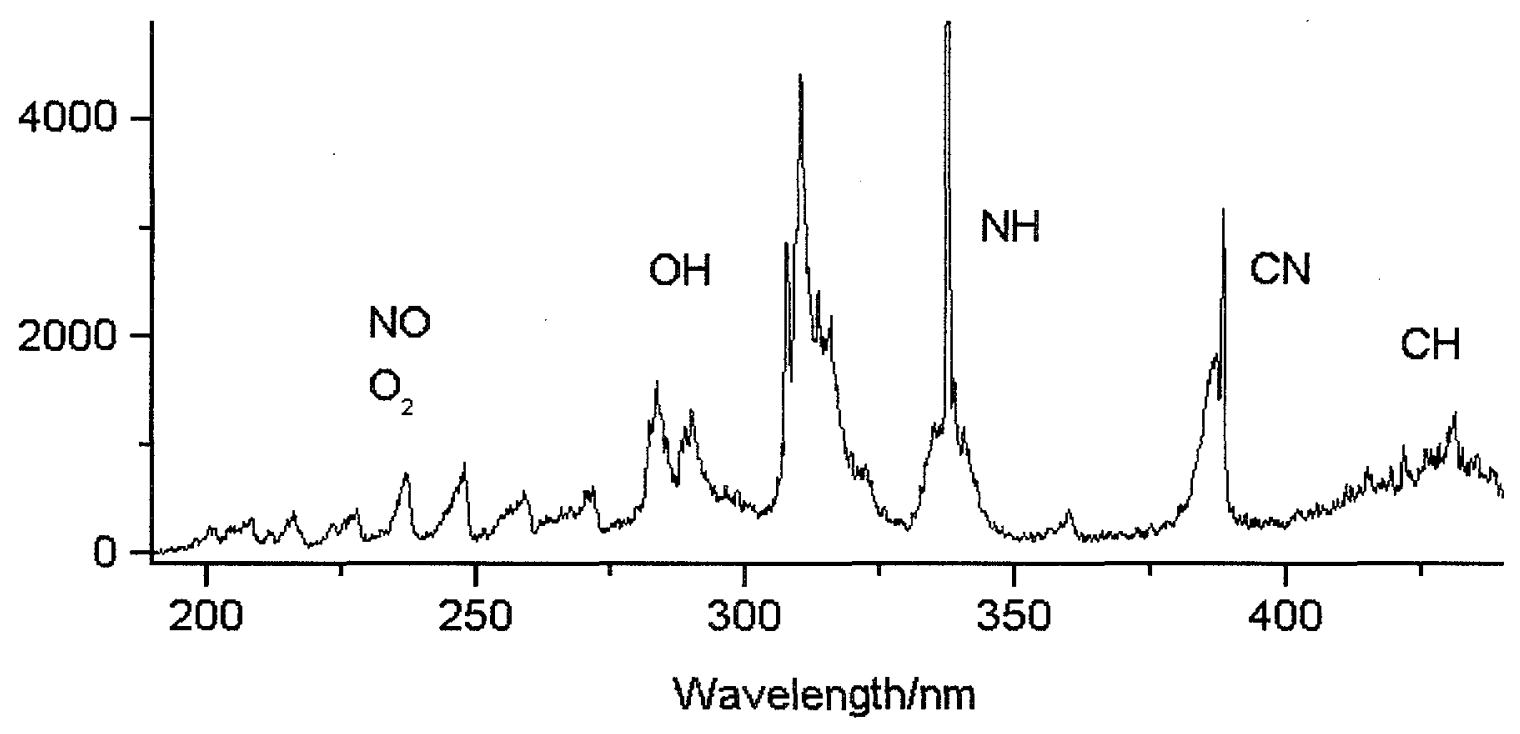

Figure 14: The emission spectrum of a HNF monopropellant flame (1 atm).

\section{HNF-BASED COMPOSITIONS}

To evaluate the effect of fuel additives on the combustion of HNF, several fuel ingredients have been pressed together with the HNF. The following additives were used in this study: aluminum, graphite and paraffin.

\section{HNF-ALUMINUM}

Aluminum is often added in a propellant to increase the flame temperature, thereby increasing the performance of a propellant. Figure 15 shows the effect of adding $20 \%$ of aluminum to HNF (average Al particle diameter $20 \mu \mathrm{m}$ ). These experiments have only been carried out with $6 \mathrm{~mm}$ pellets. Due to the sensitivity of binderless oxidizer/aluminum mixtures, no larger samples have been prepared.

The addition of aluminum enhances the burning rate app. $30 \%$, and increases the burning rate exponent from 0.95 to 1.02 . This indicates that the aluminum participates actively in the combustion process, rather than being an inert heat sink. The monopropellant flame of HNF has a very high temperature compared to e.g. AP (2766K vs. $1377 \mathrm{~K}$ at $1 \mathrm{~atm})$. This fact, and the fact that HNF has a very short flame, may cause the aluminum to ignite already at the burning surface. At low pressures there was some residue after combustion of the samples. The amount of residue decreased with increasing pressure. At pressures of $2 \mathrm{MPa}$ no residue was observed. The more efficient aluminum combustion at higher pressures, causes an enhanced heat feedback to the burning surface with increasing pressure, and can explain the increase of the burn rate exponent.

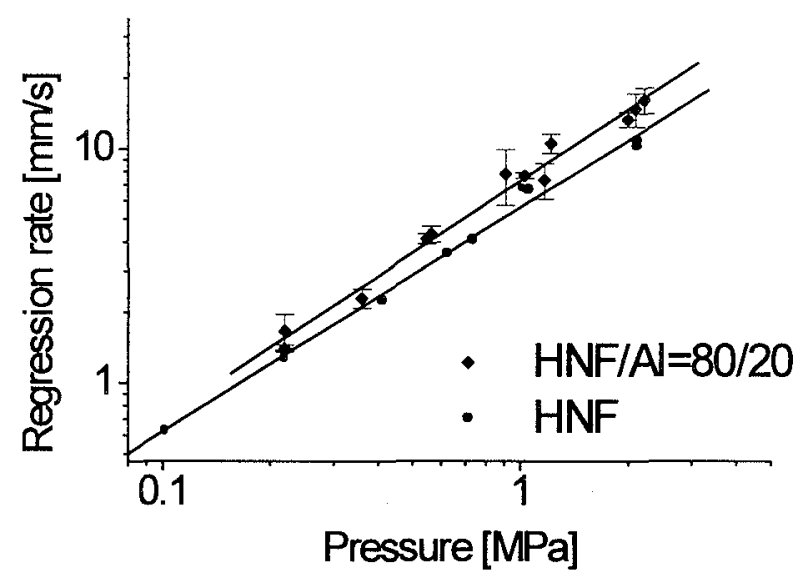

Figure 15: Regression rate of $H N F / A l=80 / 20$ mixture vs. neat HNF.

\section{HNF-GRAPHITE}

The addition of small amounts of carbon containing materials to double-base is known to influence their combustion characteristics [24]. In view of the $\mathrm{NO}_{\mathrm{x}}$-chemistry, the gas phase of HNF is very similar to that of double-base and nitramine propellants. Therefore it was decided to add $5 \%$ of graphite to HNF, to evaluate the effect. At low pressures the burn rate exponent decreases from $\mathrm{n}=0.95$ for neat HNF to $\mathrm{n}=0.81$ for $\mathrm{HNF} /$ graphite, see Fig. 16. This is caused by the higher burn rate at low pressures. At high pressures the effect disappears and the regression rates become equal, see Fig. 17. 


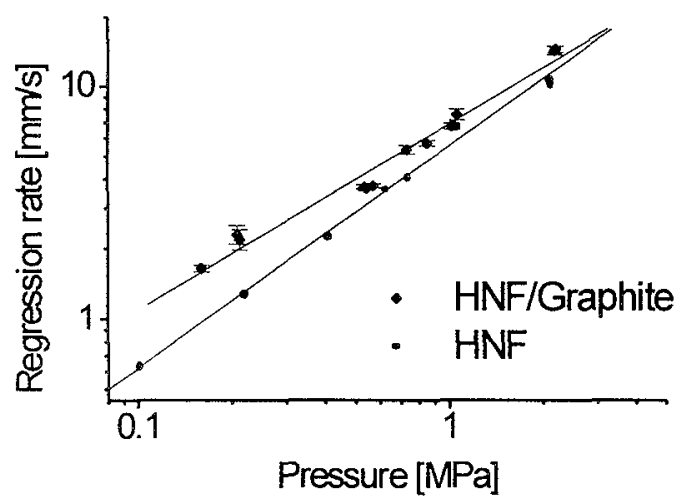

Figure 16: Regression rate of $H N F /$ Graphite $=95 / 5$ vs. neat HNF (low pressure).

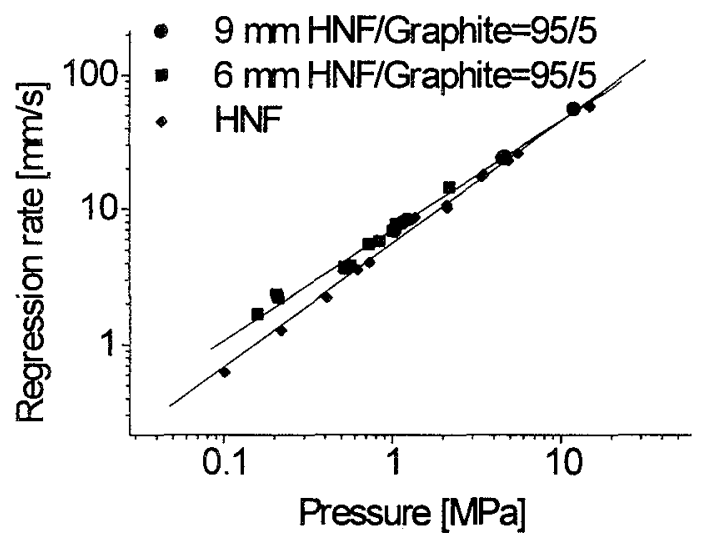

Figure 17: Regression rate of $H N F /$ Graphite $=95 / 5$ vs. neat $H N F$.

The combustion of HNF-mixtures has been modeled using a modified PREMIX-code for 1D premixed gas flames [25]. A few simple initial decomposition steps model the condensed phase. In the gas phase Yetter's kinetics for nitramines, together with the GRI-mech for hydrocarbon combustion are used [26,27]. With this model neat HNF and HNF-graphite have been calculated (with assumed equal surface temperature). Figure 18 shows the results of such a calculation. It is seen that the temperature gradient in the gas phase close to the surface is larger when graphite is added. This is caused by the combustion of the graphite by the excess oxygen of HNF. This explains the higher burn rates when graphite is added (possibly further enhanced by radiative heat feedback, see Fig. 19). At higher pressures the HNF flame is already very close to the surface. The graphite reaction is too slow under these conditions, and does not further increase the burn rate.

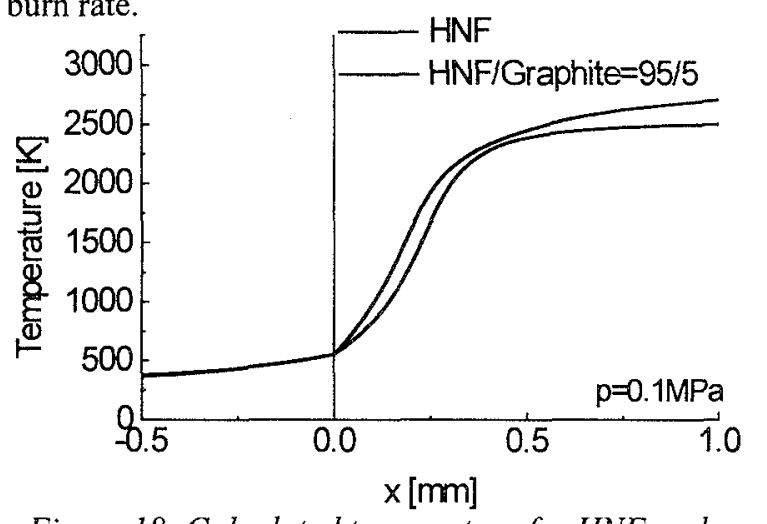

Figure 18: Calculated temperature for HNF and HNF/graphite.

\section{HNF-PARAFFIN}

Due to the incompatibility of HNF with nonenergetic binders like HTPB, an alternative representative propellant formulation was sought for. Paraffin wax is compatible with HNF. Paraffin with a melting temperature of app. $55^{\circ} \mathrm{C}$ was melted and mixed with HNF. After solidification the mixture was pressed to pellets.

Figure 20 shows the regression rate for a mixture containing $10 \%$ paraffin. This figure shows a large difference between the two experimental setups. At low pressures a thick paraffin melt layer is formed at the burning surface. The small samples are not inhibited. As a result the melted paraffin partially
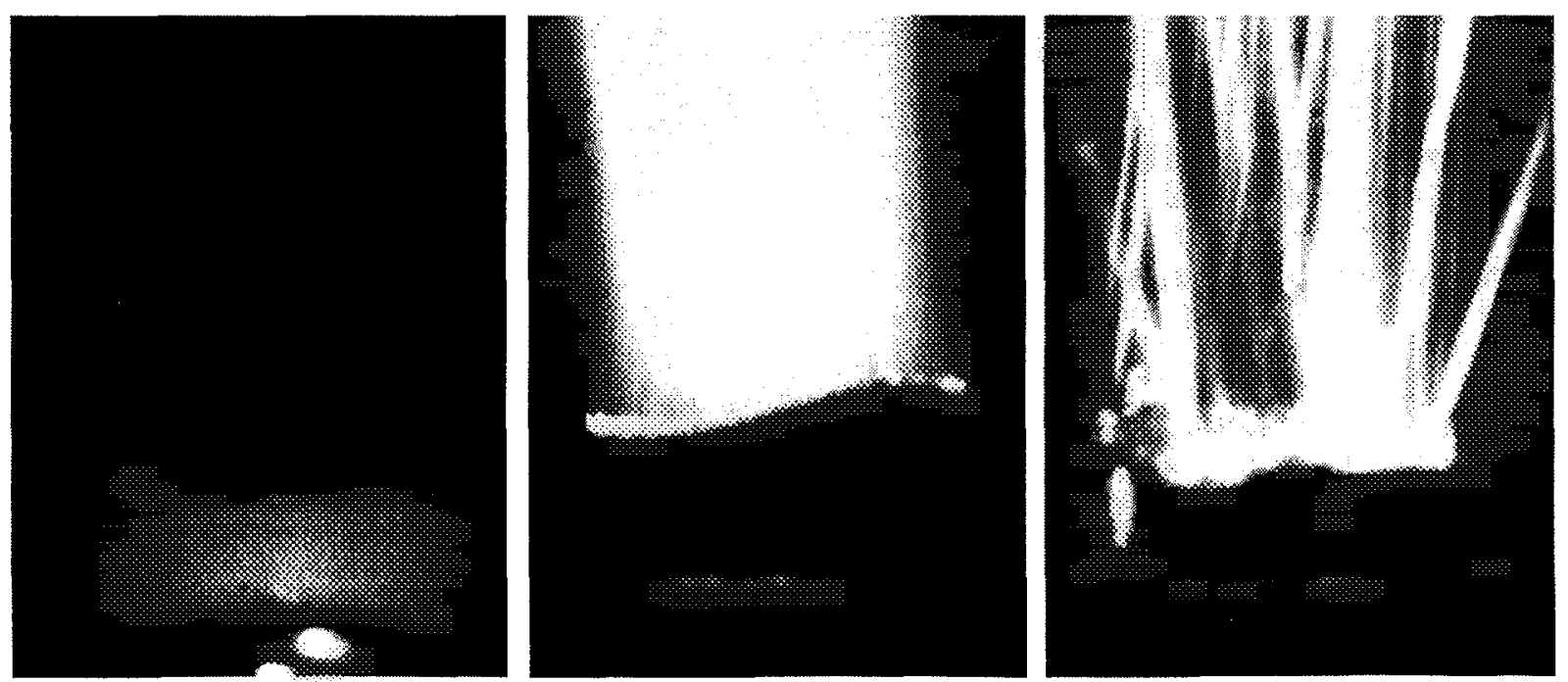

Figure 19: Images of burning samples at atmospheric pressure. Left: neat HNF, center: HNF/graphite, right: HNF/aluminum (1 atm). 
drips along from the sides, away from the burning surface. This may explain the slope break between the low and high pressure experiments, $n=0.81$ and $\mathrm{n}=1.09$ respectively.

The difference in burn rate for two different values of solid loading is depicted in Fig. 21. This figure shows that the effect of adding more paraffin is small.

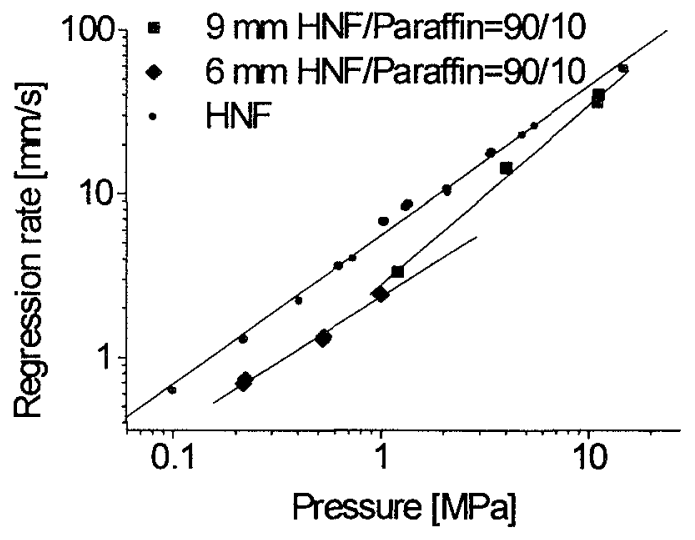

Figure 20: Regression rate of $H N F /$ Paraffin $=90 / 10$ vs. neat $H N F$.

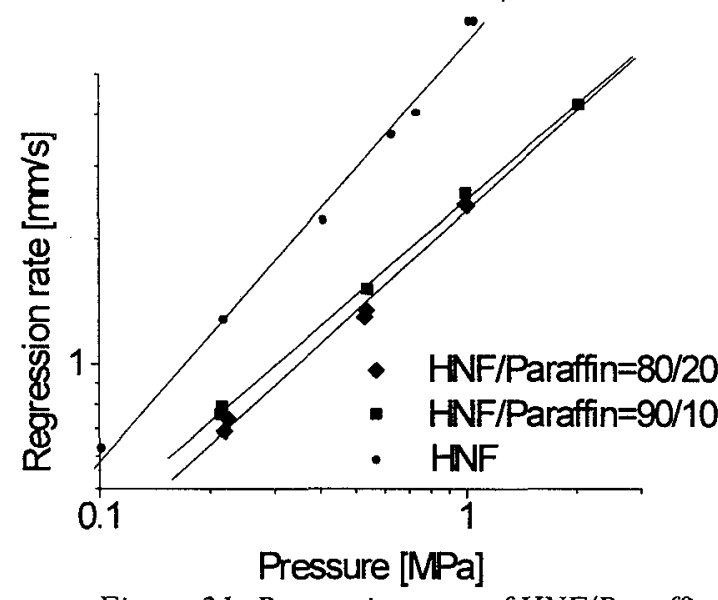

Figure 21: Regression rate of HNF/Paraffin mixtures (different solid loading).

\section{CONCLUSIONS}

Small pellets of HNF and HNF with additives have been pressed. The samples were studied in window bombs. The friction sensitivity of the neat HNF samples is equal to that of the original material $(16-24 \mathrm{~N})$. The pellets are less sensitive to impact (10 Nm vs. $2-4 \mathrm{Nm}$ ).

Neat HNF pellets burn with a high regression rate. A slope break is observed around $2 \mathrm{MPa}$ (from 0.95 to 0.85 ). The surface temperature increases with increasing pressure: at $0.1 \mathrm{MPa}$ $\mathrm{T}_{\mathrm{s}}=530 \mathrm{~K}$ and at $1 \mathrm{MPa} \mathrm{T}_{\mathrm{s}}=680 \mathrm{~K}$. The thermocouple measurements show a bend in the condensed phase temperature profile. This bend is attributed to cracks that form during combustion. Because of these cracks the thermal conductivity decreases. $\mathrm{NQ}, \mathrm{O}_{2}, \mathrm{OH}, \mathrm{NH}$, $\mathrm{CN}$ and $\mathrm{CH}$ radicals were identified in the flame by emission measurements.

Samples containing $20 \%$ aluminum have about $30 \%$ higher burn rate at $1 \mathrm{MPa}$ than neat $\mathrm{HNF}$. At low pressures, a small amount of residue was found after combustion. However, at $2 \mathrm{MPa}$ the pellets combust without residue.

Samples containing 5\% graphite have a lower pressure exponent, $\mathrm{n}=0.81$. This is caused by a higher regression rates at lower pressures. Around $10 \mathrm{MPa}$ the burn rate is equal to that of neat HNF. Also paraffin-based combination burn with low pressure exponent $n=0.81$ at low pressures. However at higher pressures an increase in pressure exponent was found, $\mathrm{n}=1.09$.

\section{ACKNOWLEDGMENTS}

This work was sponsored by the Dutch Technology Foundation, STW under project DTN 66.4108. We would like to thank Aerospace Propulsion Products (APP) for providing the HNF for this work; The pyrotechnics and energetic materials group (TNO/PML-PE) for use of their pressing equipment; Arnold Leeuwenburgh for his preparation of the HNF/paraffin mixtures; Jaap Varkevisser for his assistance with the strand burner experiments; Bart Hoek and Gerard Schreuder for the design and construction of the experimental set-up.

\section{REFERENCES}

[1] G. Doriath and B. d'Andrea, New Solid Propellants Formulations and Production Processes, $5^{\text {th }}$ Int. Symp. Propulsion in Space Transportation, Paris, 22-24 May, 1996.

[2] G.M. Low, Hydrazinium Nitroformate Propellant with Saturated Polymeric Hydrocarbon Binder, U.S. Patent 3,708,359, Jan 2, 1973.

[3] J.M. Mul, P.A.O.G. Korting, and H.F.R. Schöyer, Search for New Storable High Performance Propellants, AIAA Paper 88-3354, Boston, Massachusetts, 1988.

[4] H.F.R. Schöyer, A.J. Schnorhk, P.A.O.G. Korting, P.J. van Lit, First Experimental Results of an HNF/Al/GAP Solid Rocket Propellant, AIAA Paper 97-3131, Seattle, Washington, 1997.

[5] G.M.H.J.L. Gadiot, J.M. Mul, J.J. Meulenbrugge, P.A.O.G. Korting, A.J. Schnorhk and H.F.R. Schöyer, New Solid Propellants Based on Energetic Binders and HNF, IAF Paper IAF 92-0633, 1992.

[6] H.F.R. Schöyer, A.J. Schnorhk, P.A.O.G. Korting, P.J. van Lit, J.M. Mul, G.M.H.J.L. Gadiot and J.J. Meulenbrugge, Development of Hydrazinium Nitroformate Based Solid Propellants, AIAA Paper 95-2864, San Diego, California, 1995. 
[7] H.F.R. Schöyer, A.J. Schnorhk, P.A.O.G. Korting, P.J. van Lit, J.M. Mul, G.M.H.J.L. Gadiot and J.J. Meulenbrugge, High-Performance Propellants Based on Hydrazinium Nitroformate, J. Prop. Power 11, 856-859, 1995.

[8] G. von Elbe, . Friedman, J.B. Levy and S.J. Adams, Research on Combustion in Solid Rocket Propellants: Hydrazine Nitroform as a Propellant Ingredient, Atlantic Research Corp., Techn. Rep. DA36-034-AMC-0091 R, July 21, 1964.

[9] E. T. McHale and G. von Elbe, The Deflagration of Solid Propellant Oxidizers, Comb. Science Techn. 2, 227-237, 1970.

[10] G.K. Williams and T.B. Brill, Thermal Decomposition of Energetic Materials 67. Hydrazinium Nitroformate (HNF) Rates and Pathways under Combustionlike Conditions, Comb. Flame 102, 418-426, 1995.

[11] T.P. Parr and D.M. Hanson-Parr, HNF: Neat and Diffusion Flame Structure, 32nd JANNAF Combustion Subcommittee Meeting, 1995.

[12] T.P. Parr and D.M. Hanson-Parr, Solid Propellant Diffusion Flame Structure, $26^{\text {th }}$ Int. Symp. on Combustion, July 28 - August 2, Naples, Italy.

[13] J.C. Finlinson, Laser Recoil Combustion Response of HNF Oxidizer from 1 to $6 \mathrm{~atm}$,

AIAA Paper No. 97-3342, 1997.

[14] J.C. Finlinson and A.I. Atwood, HNF Burnrate, Temperature Sensitivity, and Laser Recoil Response from 1 to $6 \mathrm{~atm}, 34^{\text {th }}$ JANNAF Comb. Meeting, West Palm Beach, Florida, 27-31 Oct. 1997.

[15] J. Louwers, T.P. Parr and D.M. Hanson-Parr, Unpublished results 1997.

[16] D.M. Hanson-Parr and T.P. Parr, Measurements of Solid Rocket Propellant Oxidizers and Binder Materials as a Function of Temperature, submitted to J. Energ. Mat., 1997.

[17] V.A. Koroban, T.I. Smimova, T.N. Bashirova and B.S. Svetlov, Kinetics and Mechanisms of the Thermal Decomposition of Hydrazin Trinitromethane, Tr.-Mosk. Khim-Tekhnol. Inst. im. D. I. Mendeleeva 104, 38-44, 1979.

[18] H. Hatano, T. Onda, S. Kiname, S. Suzuki, Characteristics of HNF, 20 $0^{\text {th }}$ Int. Pyrotechnics Seminar, Colorado Springs, Colorado, 25-29 July, 1994.

[19] T. Anan and T. Harada, Physical and Chemical Properties of HNF, Kayaku Gakkaishi 56, 99-104, 1995.

[20] J. Louwers, G.M.H.J.L. Gadiot M.Q. Brewster, S.F. Son, Model for Steady-State HNF Combustion, Int. Workshop on Combustion Instability of Solid Propellants and Rocket Motors, Politecnico di Milano, Italy, 16-19 June 1997.

[21] J. Louwers, G.M.H.J.L. Gadiot, Model for the Transient Burning of Hydrazinium Nitroformate, Int. Workshop on Combustion Instability of Solid Propellants and Rocket Motors, Politecnico di Milano, 16-19 june 1997.
[22] J. Louwers, G.M.H.J.L. Gadiot, M. Versluis, A-J. Landman, Th.H. vd Meer and D. Roekaerts, Measurement of Steady and Non-Steady Regression Rates of Hydrazinium Nitroformate with Ultrasound, Int. Workshop on Measurement of Thermophysical and Ballistic Properties of Energetic Materials, Politecnico di Milano, Milano, Italy, 22-24 June 1998.

[23] Communication with Dr. N. Kubota, 1998.

[24] N. Kubota, T.J. Ohlemiller, L.H. Caveny, and M. Summerfield, An Experimental Study of the Site and Mode of Action of Platonizers in Double-Base Propellants, AIAA Paper 81-1555, 1981.

[25] R.J. Kee, J.F. Grcar, M.D. Smooke, and J.A. Miller, A Fortran Program for Modeling Steady Laminar One-Dimensional Premixed Flames, Sandia National Laboratories, Report SAND85-8240, 1985.

[26] R.A. Yetter, F.L. Dryer, M.T. Allen, and J.L. Gato, Development of Gas-Phase Reaction Mechanisms for Nitramine Combustion, J. Prop. Power 11, 683-697, 1995.

[27] C.T. Bowman, R.K. Hanson, D.F. Davidson, W.C. Gardiner Jr., V. Lissianski, G.P. Smith, D.M. Golden, M. Frenklach and M. Goldenberg, http://www.me.berkely.edu/gri_mech/ .

\section{ACRONYMS}

ADN Ammonium Dinitramide

AP Ammonium Perchlorate

APP Aerospace Propulsion Products

BAMO Poly 3,3-Bis(AzidoMethyl) Oxetane

DSC Differential Scanning Calorimeter

ESA European Space Agency

GAP Glycidyl Azide Polymer

HMX Cyclotetramethylene Tetranitramine

HNF Hydrazinium Nitroformate

HNIW Hexanitrohexaazaisowurtzitane, CL-20

HTPB Hydroxy-Terminated Polybutadiene

LIF Laser-Induced Fluorescence

PML Prins Maurits Laboratory

NAWC Naval Air Warfare Center

RDX Cyclotrimethylene Trinitramine

TMD Theoretical Maximum Density

ZnSe Zinc Selenide 